the pioneers of sex research - and the current gallery will be spruced up before relaunching in October with a show on forensics. The glorious reading room will be made open to all as a place in which objects gathered by medical collector extraordinaire Henry Wellcome keep company with rare books, art and more.

\section{Interstellar}

Director Christopher Nolan

Opens 7 November

In a future near you, societal order has collapsed and the remnants of NASA are cobbled together to investigate a tear in the fabric of the Universe. Interstellar, already touted as one of the big films of 2014, will be a long-awaited cinematic outing for the ideas of theoretical physicist Kip Thorne, who advised on the venture. Breaking away from the idea that space exploration is limited to the Solar System, Thorne plays with the possibility of time travel using wormholes - 'warps' in space-time that serve as shortcuts to distant parts of the Universe. Christopher Nolan, who bent minds with 2010's heist-within-a-dream-within-adream thriller Inception, directs.

\section{Russia's Space Quest}

Science Museum, London Autumn 2014

In 2014, Russia and Britain celebrate a joint year of culture, and the programme's flagship event will be this showing of a remarkable collection of Soviet space artefacts. Visitors will be able to savour the sight of the capsules that carried cosmonauts aloft and the rocket engines that powered them, alongside smaller items from personal memorabilia to spacesuits. A collaboration with Moscow's Memorial Museum of Cosmonautics and

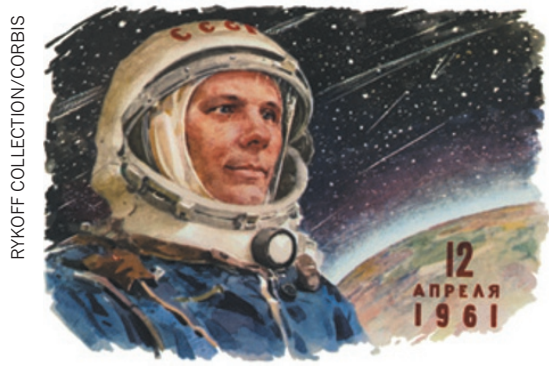

Soviet propaganda celebrated the first human trip into space, by Yuri Gagarin.

the Russian space agency, Roscosmos, the show represents the most significant collection of such items ever permitted to leave Russia. .

Daniel Cressey is a reporter for Nature in London. Additional reporting by Alison Abbott and Barbara Kiser.

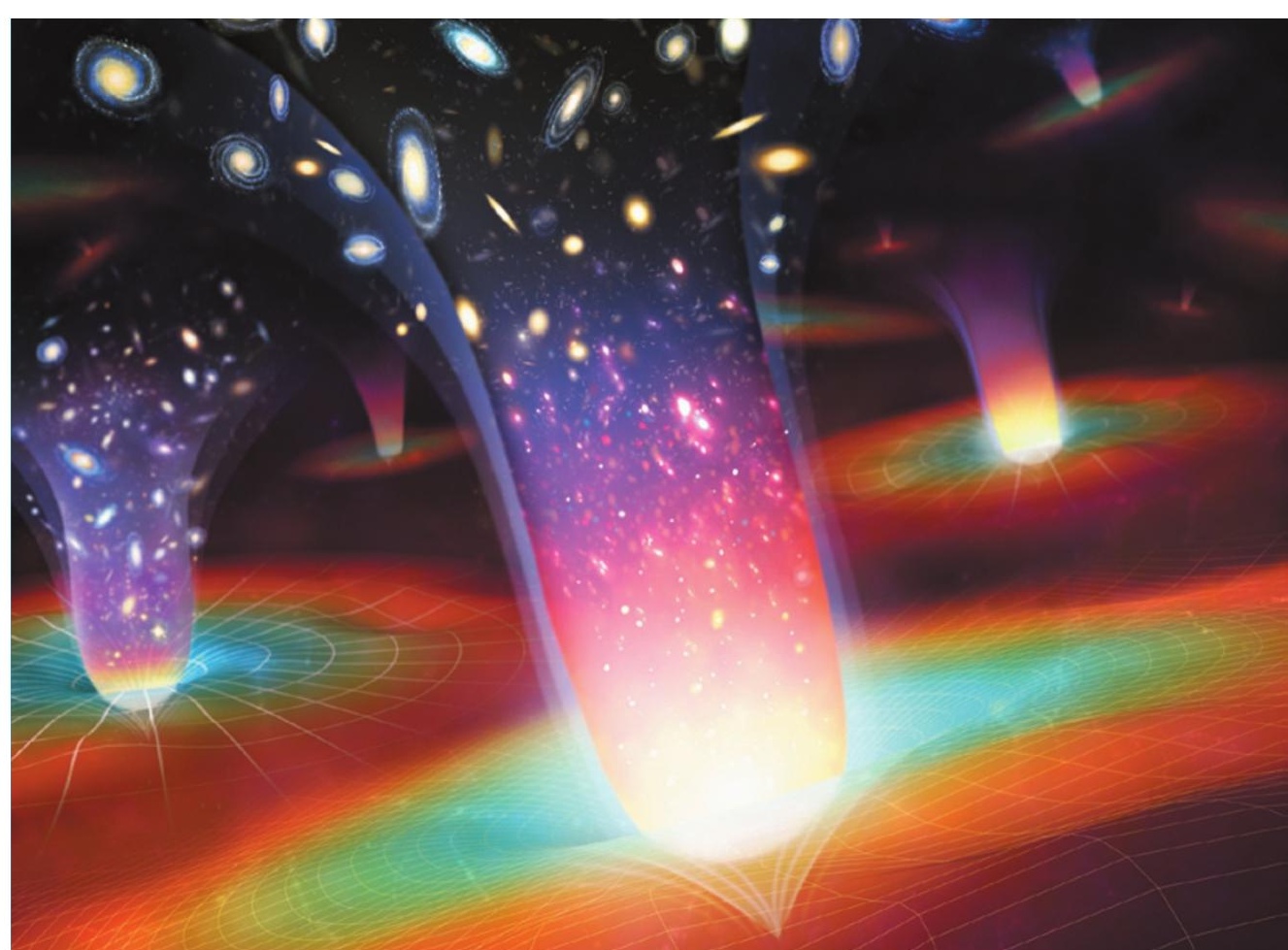

PHYSICS

\title{
Chasing universes
}

\section{Andrew Liddle contemplates an accomplished explication of the multiverse.}

$\mathrm{H}$ aving trouble understanding the Universe? Try this instead: imagine $10^{500}$ possible universes, all different, and consider our place within this ensemble. Not randomly chosen, because our location should satisfy some basic conditions, such as habitability for intelligent species able to ask about their place in the cosmos. Can such a multiverse help us to fathom our Universe?

Cosmologist Max Tegmark has written an engaging and accessible book, Our Mathematical Universe, that grapples with this multiverse scenario. He aims initially at the scientifically literate public, but seeks to take us to - and, indeed, beyond - the frontiers of accepted knowledge. His explication of these ideas is more ambitious and individualistic than books on this topic by Leonard Susskind and Alex Vilenkin, for instance.

Multiverse theory stands in stark opposition to the belief that there should be some reason, perhaps a Theory of Everything, that determines physical laws such as the types $\checkmark$ NATURE.COM and the ways in which Formore on the they interact. In the multiverse, see: multiverse picture, go.nature.com/mgc2jd it is all an accident.
Our Mathematical Universe: My Quest for the Ultimate Nature of Reality MAX TEGMARK

Knopf: 2014.

What we know as 'constants' of nature, such as the strength of gravity or the proton-toneutron mass ratio, happen to have particular values here, but in distant regions beyond our sight they may take other values and produce universes with very different properties - perhaps an absence of complex atoms and molecules, and hence of life.

Once seen as a fringe interest of dubious scientific validity, the multiverse has developed a serious following. Steven Weinberg used it in 1987 to predict that our observable Universe ought to have a non-zero cosmological constant, probably of a magnitude great enough to accommodate the acceleration of the Universe's expansion. To everyone's surprise, this was verified a decade later through observations of distant supernovae by two teams of astronomers. Those who led the work, Saul Perlmutter, Adam Riess and Brian Schmidt, won the 2011 Nobel Prize in Physics. Subsequently, string theory and inflationary cosmology were recognized as 
$\overrightarrow{0}$ providing a setting that could predict, or at least motivate, the existence of a multiverse.

Tegmark's book captures two trends in contemporary science writing: scientific autobiography and the popular book as manifesto, expressing a body of personal scientific ideas ill-suited to traditional academic journals. Accordingly, Tegmark interweaves the science with stories of personal contributions to the endeavour. Fortunately, he is an engaging host. Tegmark makes his manifesto explicit by chopping his research life into two parts. Around a quarter of the book covers the 'sensible' work on constraining cosmological models from data. The rest is the outlandish part on quantum realities and multiple universes - even including an e-mail from a (sadly unnamed) senior academic advising him to desist before he destroys his career. It is clear where Tegmark's priorities lie: this book is his statement on the multiverse as a valid model for reality.

Tegmark likes the multiverse so much that he doesn't settle for just one; instead, he offers four different levels of multiverse. In the first, we simply have our own Universe, with its physical laws, extending forever. Shockingly, this is sufficient to ensure that, somewhere far away, there are exact replicas of you reading this review, on exact replicas of Earth. It might even be enough to imply that you are more likely to exist within a simulation of reality than in reality itself (whatever that means).

In the second incarnation, perhaps the most popular among proponents, physical laws vary within the multiverse so that distant regions can be considered to be distinct universes. This version is necessary to explain, for instance, the cosmological constant and other apparent coincidences in physical laws such as the stability of neutrons within nuclei. In the third level, the parallel universes may exist only as quantum mechanical states.

The culmination that Tegmark seeks to lead us to is the "Level IV multiverse". This level contends that the Universe is not just well described by mathematics, but, in fact, is mathematics. All possible mathematical structures have a physical existence, and collectively, give a multiverse that subsumes all others. Here, Tegmark is taking us well beyond accepted viewpoints, advocating his personal vision for explaining the Universe.

This is a valuable book, written in a deceptively simple style but not afraid to make significant demands on its readers, especially once the multiverse level gets turned up to four. It is impressive how far Tegmark can carry you until, like a cartoon character running off a cliff, you wonder whether there is anything holding you up.

Andrew Liddle is a theoretical cosmologist at the Institute for Astronomy, University of Edinburgh, UK.

e-mail:arl@roe.ac.uk

\section{Books in brief}

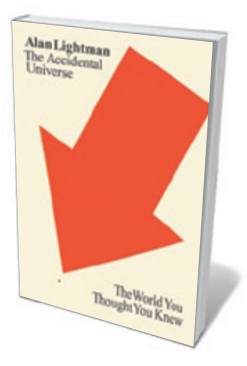

The Accidental Universe: The World You Thought You Knew Alan Lightman PANTHEON (2014)

Theoretical physicist Alan Lightman's meditation on how recent findings in science shape our concept of self and Universe unfolds with the mesmeric calm of a vessel in space. That is, until he treats us to some split-second encounter with a sliver of the totality - such as the eye of a flying osprey. In seven elegant essays on aspects of the Universe, Lightman takes us from the idea of an accidental cosmos, prompted by multiverse theory, to the Higgs boson, digital disembodiment and the cosmic evanescence that fits so poorly with our longing for permanence.

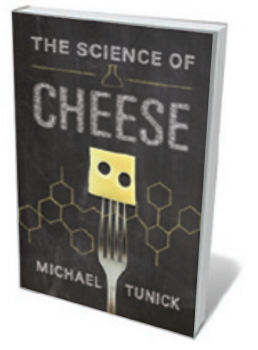

\section{The Science of Cheese}

Michael Tunick OXFORD UNIVERSITY PRESS (2013)

From "smear-ripened" Swiss tilsit to the maggot-riddled casu marzu of Italy, cheese can carry a whiff of the surreal. Chemist Michael Tunick tours a sample of the 2,000 known varieties, mingling science (biology, chemistry, physics, nutrition and climatology) and cultural lore to make an accessible whole. If you have ever wondered what links Limburger with foot perspiration (answer: short-chain fatty acids), or how to make mozzarella at home, Tunick is your man. And the world's most expensive cheese? Made from moose milk on a Swedish farm, it will set you back US $\$ 1,000$ a kilogram.

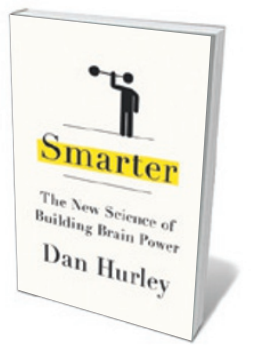

\section{Smarter: The New Science of Building Brain Power}

Dan Hurley HUDSON STREET PRESS (2013)

Is "fluid" intelligence - the ability to think on your feet and discern patterns - teachable? In this trip through the findings on and controversies around brain training, science journalist Dan Hurley proves an able, often caustically humorous guide. He starts with 2008 research on working-memory training by psychologists Susanne Jaeggi and Martin Buschkuehl, then trawls research in areas such as gaming and visual attention processing. After taking the pulse at science conferences and turning guinea pig to test a range of techniques, Hurley admits to cautious optimism.

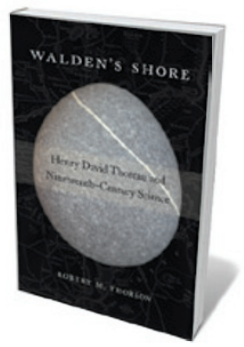

Walden's Shore: Henry David Thoreau and Nineteenth-Century Science

Robert M. Thorson HARVARD UNIVERSITY PRESS (2013)

In his 1854 masterpiece Walden, the US writer and naturalist Henry David Thoreau invites us to "wedge our feet downward ... till we come to a hard bottom and rocks in place, which we can call reality". Geologist Robert Thorson obliges, focusing on Thoreau as a flinty amateur geologist to reinject science into his literary legacy. Thoreau, Thorson persuasively argues, was as grounded in rock as he was in the elemental understanding of the cosmos sought by the Transcendentalist movement.

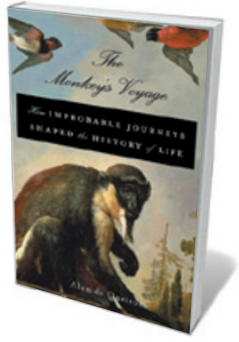

The Monkey's Voyage: How Improbable Journeys Shaped the History of Life

Alan de Queiroz BASIC Books (2014)

Biogeography is undergoing a sea change, argues Alan de Queiroz. The dominant theory of global species dispersal previously centred on the break-up of the supercontinent Gondwana, starting some 160 million years ago. Now, the idea of species traversing oceans is gaining ground. Perhaps the most compelling scenario is the 'monkey transfer' from Africa to South America, envisioned as a simian troop hitching a ride on an uprooted, floating tree. Barbara Kiser 